\title{
Compromiso social y convivencia ciudadana en tiempos de pandemia por COVID-19
}

\author{
Social commitment and citizen coexistence in times of pandemic by \\ COVID-19
}

Marta Sahagún-Navarroa $\mathbb{C D}^{;}$Yuly-Marcela Parra-Montoyab ${ }^{\text {(B) }}$

"Tener fuertes convicciones es el secreto para sobrevivir a las privaciones, tu espíritu puede estar lleno, incluso cuando tu estómago está vacío"

Nelson Mandela, 1994

La nueva enfermedad del coronavirus humano COVID-19 se ha convertido en la quinta pandemia documentada desde la pandemia de gripe de 1918 (Liu Y-C et al., 2020). También, ha sido la mayor interrupción en el movimiento de personas desde la Segunda Guerra Mundial (Newland, 2020), lo que ha conllevado a periodos extendidos de cuarentena, órdenes de cierre masivo de refugio en el hogar y negocios, que imponen serias libertades y privaciones económicas (Mello \& Wang, 2020), en la mayoría de los países del mundo por la enfermedad que origina. Esto ha modificado las dinámicas sociales, económicas y políticas, desde los niveles institucionales y lógicamente, en los individuos.

Actualmente, más de doce millones de personas han sido contagiadas y más de quinientas mil han fallecido (WHO, 2020). En ausencia de una vacuna, el control del COVID-19 depende de las estrategias de mitigación de la comunidad que requieren apoyo público para ser efectivas (Czeisler, Tynan, Howard \& et.al, 2020). Esto sin duda nos pone en sintonía para repensar una sociedad que ha sido dividida por el individualismo y la satisfacción de necesidades personales, para abocarnos a la unión de fuerzas y manos en aras de una solidaridad subyacente.

Las acciones tomadas en distintos países para la contención del virus han conllevado a nuevas dinámicas de convivencia, donde los valores representan una forma de vivir: comportamientos, sentimientos, conocimientos y acciones relacionadas con la identidad de cada persona se interrelacionan y conviven entre sí (Ethel-Durán, García-Guiliany, Parra-Fernández, 2017). Al respecto, la pandemia ha registrado emociones positivas, tales como la empatía, el amor y la solidaridad, pero también síntomas negativos como el miedo, la frustración, la ansiedad, el aburrimiento, que pueden conllevar -si se prolongan demasiado- a diversos trastornos mentales de tipo traumático, ansioso, somático o depresivo (Flores, 2020).

aEditora en Jefe, Corporación Universitaria del Caribe CECAR. revistabusqueda@cecar.edu.co

bEditora Asociada. Corporación Universitaria del Caribe CECAR. revistabusqueda@cecar.edu.co

Como citar (APA)

Sahagún-Navarro, M.; Parra-Montoya, Y. (2020). Compromiso social y convivencia ciudadana en tiempos de pandemia por COVID-19. Búsqueda, v. 7, n. 24, e488. https://doi.org/10.21892/01239813.488 
Con el propósito de aportar soluciones a esta crisis sanitaria, social y económica provocada, las organizaciones han realizado cambios en sus cadenas de producción tradicional, poniéndose al servicio de las nuevas necesidades, por ejemplo, a través de la fabricación de alcohol isopropílico, mascarillas y batas de protección. Según un estudio realizado por el Centro de Innovación y Emprendimiento, INCUBA y el Grupo de Estudios en Administración del CESA (GEA), se estima que los emprendimientos se han incrementado y sus esfuerzos se han redirigido a la utilización de nuevas tecnologías y canales de distribución diversos que permitan seguir en pie durante y después de la contingencia.

Finalmente, lo que muchos nos preguntamos es ¿Cuándo durará el confinamiento? Sin embargo, mientras esperamos una posible reapertura, la consideración puede ser establecida desde el ¿Cómo enfrento el confinamiento? Es considerar la invitación a redirigir la situación desde un punto de quiebre para reflexionar y poder moldear como sociedad una nueva realidad, lo que nos enfrenta también a nuevos aprendizajes relacionados con el consumo responsable y la adaptación al cambio.

En la revista Búsqueda tenemos el deber de difundir información contrastada, verídica y ajustable a estos tiempos de innumerables cambios sociales y económicos. Por ello, lanzamos el número 24 con una nueva web, actualizada y usable, con el fin de difundir los estudios realizados, siempre en agradecimiento a todos los investigadores que siguen en lucha por visibilizar las problemáticas sociales que nos acontecen. Continuamos invitando a la comunidad científica a someter sus artículos científicos para su potencial publicación.

iGracias por su confianza!

\section{REFERENCIAS}

Czeisler M. É.; Tynan, M. A.; Howard, M. E.; et al. (2020). Actitudes, comportamientos y creencias públicas relacionadas con COVID-19, órdenes de quedarse en casa, cierres de negocios no esenciales y orientación sobre salud pública. MMWR Morb Mortal Wkly Rep; 69, 751-758. http://dx.doi.org/10.15585/mmwr.mm6924e1

Ethel-Durán, S.; García-Guiliany, J. E.; Parra-Fernández, M. (2017). Diversidad cultural y fomento de valores en la convivencia ciudadana. Búsqueda, 4(19), 116-130. https://doi. org/10.21892/01239813.366

Flores, R. (2020). Miedo, ansiedad, frustración, aburrimiento... efectos colaterales de la pandemia. https://www.proceso.com.mx/624517/miedo-ansiedad-frustracion-aburrimiento-efectoscolaterales-de-la-pandemia

Liu, Y-C.; Kuo, R. L.; Shih, S. R. (2020). COVID-19: The first documented coronavirus pandemic in history. Biomedical Journal, https://doi.org/10.1016/j.bj.2020.04.007

Mello, M. M.; Jason-Wang, C. (2020). Ethics and governance for digital disease surveillance. Science, 368(6494), 951-954. http://dx.doi.org/10.1126/science.abb9045

Newland, K. (2020) Lost in transition. Editorial, vol. 368, Número 6489, págs. 343. http://dx.doi. org/10.1126/science.abc3197

Revista Dinero (11 de julio de 2020) Revista Dinero. https://www.dinero.com/emprendimiento/ articulo/pandemia-impacto-positivamente-al-16-de-emprendimientos-en-colombia/290287

WHO (2020). WHO Coronavirus Disease (COVID-19). https://covid19.who.int/ 